\title{
Historia oral y contemporaneidad*
}

\section{Paul Thompson**}

¿Cuál debería ser nuestra visión acerca de las potencialidades futuras de la historial oral en el umbral del Nuevo siglo? Hacerse tal pregunta inmediatamente dispara una segunda: ¿qué entendemos por "historia oral"? Para ofrecer algunas respuestas amplias a este desafío quisiera recurrir a mi propia experiencia de 30 años de trabajo en el campo de la historia oral.

En primer lugar, decididamente me inclino por una definición amplia de "historia oral" como la interpretación de la historia, las sociedades y las culturas en proceso de cambio a través de la escucha y registro de las memorias y experiencias de sus protagonistas, y por lo tanto no me parece apropiado concebirla ni como un método de trabajo minuciosamente determinado y con reglas fijas ni como una sub-disciplina separada.

En primer lugar, podríamos decir que es un método que siempre ha sido esencialmente interdisciplinario, una especie de cruce de caminos entre la sociología, la antropología, la historia y los análisis literarios y culturales. Haber sido testigo en mi propia experiencia de investigación de cómo disciplinas particulares pueden ser transformadas por nuevas modas metodológicas, me reveló en cierta medida que la fuerza crucial de la historia oral descansa sobre una forma fundamental de interacción humana que trasciende las fronteras disciplinarias.

* Este texto fue originalmente presentado como una conferencia pública en la Universidade Federal de Minas Gerais en Belo Horizonte, el 29 de agosto de 2000. Traducción del Inglés: Marisa Armida.

** Master of Arts: Grado académico situado entre la licenciatura en letras y el doctorado (N. de T.). 
Historia, memoria y pasado reciente

Mi propio trabajo con la historia oral surge de tal contexto interdisciplinario ya que, formado en la historia social, a partir de 1964 me dediqué a la enseñanza en el Departamento de Sociología en la Universidad de Essex. Fueron mis colegas sociólogos de esa Universidad quienes, cuando me ofrecieron escribir la historia social de Gran Bretaña en las primeras dos décadas del siglo XX -que luego se convertiría en mi libro The Edwardians (1975)- me alentaron a entrevistar hombres y mujeres que habían vivido durante ese período. Gran parte del método que adopté, incluyendo el uso de muestras estadísticas y de una extensa guía de entrevistas, también venía de la influencia sociológica. Por otro lado, en esa etapa concebí este "método" -y apelo a este término porque en aquella época no se hablaba todavía de "historia oral"- como el utilizado en las entrevistas en historia social y por consiguiente mi interés estaba puesto en el pasado de mis entrevistados más que en sus experiencias de vida más recientes. La consecuencia de ello fue que a ninguno de los 444 hombres y mujeres que grabé les pregunté nada acerca de sus experiencias después de 1920, una omisión que hizo que sus testimonios fueran, tanto histórica como sociológicamente, menos valiosos de lo que potencialmente eran, hecho que retrospectivamente lamenté mucho.

El desarrollo de mi trabajo en el marco de la sociología, y particularmente la influencia de colegas sociólogos como Daniel Bertaux, me condujeron hacia una perspectiva más amplia que fusionara el interés tanto en el pasado como en el presente a través del uso de entrevistas basadas en una única historia de vida o de grupos de entrevistas transgeneracionales realizadas a determinadas familias. Dos de mis recientes libros que ejemplifican este abordaje son Pathways to Social Class (1997) y Growing Up In Stepfamilies (1997), estudios ambos de carácter tanto histórico como sociológico. Para el libro sobre familias postizas, grabamos entrevistas de historia de vida con 50 hombres y mujeres, todos nacidos en 1958 y quienes alrededor de los 16 años de edad habían experimentado el nuevo casamiento de uno de sus padres. Los entrevistados fueron elegidos para un estudio grupal nacional, por lo que habían sido interpelados en intervalos a lo largo de su vida, pero nunca en profundidad, y a pesar de que cuando grabamos estas entrevistas estaban recién en mitad de sus treinta años, fue muy llamativo constatar cómo aquellas infancias muy cercanas pertenecían sin embargo a una época ya desaparecida -por ejemplo, un período de pleno empleo, donde el uso de drogas no tenía la profusión que adquiriría luego y donde el divorcio era todavía infrecuente- lo que las convertía en experiencias históricas. 
Indudablemente también hay vínculos muy estrechos entre el trabajo de la historia oral y la antropología. Por supuesto que existe una larga tradición de trabajo con historias de vida en la antropología norte y latinoamericana, incluyendo clásicos tales como Pedro Martínez de Oscar Lewis o Worker in the Cane de Sidney Mintz. Si bien es lamentable que tales entrevistas no sean siempre grabadas y Lewis ha sido a menudo criticado por sus ideas simplistas sobre la "cultura de la pobreza", éstos han sido libros sumamente eficaces a la hora de transmitir la experiencia de otras culturas a vastas audiencias occidentales. Y viceversa, en mi propio trabajo he estado influenciado por la antropología, tanto en la interpretación como en el método, al punto que he venido interesándome crecientemente en el poder del mito sobre la modelación de nuestra vida cotidiana así como en la influencia transgeneracional desarrollada al interior de las familias (The Myths We Live By, 1990, y Between Generations, 1993). En algunas de mis investigaciones, junto con entrevistas grabadas he utilizado también abordajes antropológicos tales como la observación participante para Living the Fishing y para mi trabajo actual sobre familias jamaiquinas transnacionales. En el marco de estas investigaciones, por ejemplo, me involucré personalmente en la vida cotidiana de mis entrevistados navegando junto a ellos en los botes de pesca de la caballa, hablando en el puerto con viejos capitanes retirados, viviendo con una familia en una villa rural jamaiquina o participando de un oficio funerario local, por supuesto que siempre manteniendo en mente en todos esos momentos los detalles claves para poder volcarlos luego en mis notas relativas al trabajo de campo. Creo que ese tipo de combinación interdisciplinaria de métodos tiene el mayor potencial para la investigación en el futuro.

También existen importantes conexiones entre la historia oral y el trabajo social. El equipo de investigación que trabajó en Growing Up In Stepfamilies era multidisciplinario, incluyéndome a mí como historiador social y sociólogo junto con dos terapeutas familiares y un psiquiatra. Todos estábamos interesados en que el libro fuera no sólo una interpretación retrospectiva sino que también ofreciera sugerencias prácticas para futuros padres e hijos involucrados en la experiencia de convivir en el seno de familias postizas. Más en general, creo que los historiadores orales pueden realizar un análisis de mayor riqueza si al interpretar las historias de vida que registran son sensibles a los aspectos psicológicos y en este sentido, si bien existen por supuesto importantes hallazgos del psicoanálisis, como las nociones de memoria y represión, de sexualidad y 
Historia, memoria y pasado reciente

especialmente de fijaciones, usualmente es muy difícil conectarlos en la práctica con las evidencias de la historia oral que tratan más con lo recordado que con lo reprimido, más con la adultez que con la infancia. Por estas razones, es a menudo más fácil recurrir a la evidencia surgida de la investigación psiquiátrica sistemática, como la de Michael Rutter o George Brown, o de las teorías y prácticas incorporadas por terapistas familiares, quienes interpretan a las familias como sistemas estructurales entrelazados, tanto a nivel afectivo como social. Algunas veces sin embargo me ha sorprendido el nivel de resistencia que pueden llegar a oponer los sociólogos al análisis de la dimensión psicológica. Recientemente estuve discutiendo con una amiga brasileña su investigación sobre turismo sexual, en el cual aparecen como elementos manifiestamente cruciales tanto la desigualdad social (la pobreza de las mujeres brasileñas en contraste con el poder adquisitivo de los turistas) como las imágenes opuestas que unos tienen de los otros: los turistas imaginan a la mujeres brasileñas como altamente sexuales, "tropicales", mientras las mujeres conciben a los varones extranjeros como fríos y sexualmente no demandantes. Pero si bien estas presiones estructurales establecen el contexto para el turismo sexual, no explican porqué determinadas mujeres se convierten en prostitutas y otras no. Uno puede suponer que en esta situación se hallan involucrados factores de orden psicológico, tales como el abandono en la niñez, una madre distante y fría o padres o abuelos abusivos. Creo que tanto las perspectivas sociales como psicológicas son igualmente relevantes a la hora de abordar este tipo de interpretación.

En términos de trabajo social, en Gran Bretaña el desarrollo más importante de historia oral desde la década de 1970 fue la "reminiscencia terapéutica", que tuvo su origen en un efecto accidental que notamos en algunas de nuestras primeras entrevistas: algunas veces, una persona mayor que había estado enferma, muy dolorida o deprimida, luego de la entrevista, y tal como surgiera de subsecuentes reportajes a algún familiar, experimentaba una mejoría tanto física como emocional. El trabajo de reminiscencia, fue desarrollado en Gran Bretaña especialmente bajo la dirección de Joanna Bornat, que estudió conmigo en Essex durante la década del ' 70 , y se centra en grupos de discusión sobre experiencias de vida compartida, estimulados mediante una combinación de viejas fotografías, música y registros de memorias de tempranos períodos de la vida de sus participantes. Se ha descubierto que para mucha gente mayor $-\mathrm{y}$ esto es particularmente notable en aquellos que están aislados o deprimidos, aún al extremo de ya ni siquiera querer hablar- estas reminiscencias 
grupales se convierten en un punto de inflexión vital al reavivar un interés activo en la vida y en las relaciones sociales con otros y, por esta razón, esta técnica está siendo ampliamente utilizada por trabajadores sociales y sanitarios.

Desde el punto de vista del desarrollo del área laboral, tal como Hugo Slim y yo hemos argumentado en Listening for a Change (1993), la necesidad de recurrir a la experiencia plasmada en las historias de vida de la gente del lugar, ricos y pobres, hombres y mujeres es crucial si hay algún deseo de tener éxito en el diseño de programas asistenciales adecuados. Así, por ejemplo, un programa de asistencia para la industria de la pesca en Kerala se centró completamente en el financiamiento para la adquisición de botes de mayor envergadura, porque esto era lo que los pescadores reclamaban. Sin embargo, los hombres representaban solamente la mitad de la industria, el procesamiento y la comercialización del pescado era llevado adelante por las mujeres de las mismas familias y posteriormente, escuchando también sus historias, se reconoció que además de los botes existía una necesidad igualmente imperiosa de inversión en infraestructura y equipos para faenar, conservar y vender los productos de la pesca.

En segundo término, creo que la mejor investigación de historia oral es aquella que abarca tanto la comprensión e interpretación de vidas individuales como un análisis social más amplio, en otras palabras la que articula los resultados de la investigación cualitativa con los de la investigación cuantitativa. Esta perspectiva ha estado siempre presente en mi propia práctica, por ejemplo, en el caso de Growing Up In Stepfamilies, las familias postizas fueron extraídas de una muestra nacional mientras que para The Edwardians construimos nuestra propia muestra nacional. Sin embargo, muchos investigadores sociales se concentran exclusivamente en uno u otro tipo de análisis de modo que tenemos, por un lado, investigadores que se centran exclusivamente en estadísticas, utilizan encuestas basadas en cuestionarios nacionales y que tal vez en muchos años no han llevado a cabo personalmente trabajo con entrevistas o, por otro lado, investigadores que utilizan sólo métodos cualitativos enfrascados en un precioso puñado de entrevistas realizadas por ellos mismos pero incapaces de extraer ninguna probable conclusión, y por lo tanto a menudo conducidos a retraerse o bien a un análisis puramente narrativo o bien a una reflexión personal en relación a los registros orales. La historia oral que presta atención a la muestra, o mejor aún, que se vincula con muestras de una encuesta más abarcativa representa un importante 
Historia, memoria y pasado reciente

potencial para cerrar la brecha y de esta manera fortalecer ambos tipos de investigación.

Por supuesto que existen límites claros a lo que podemos extraer solamente de las estadísticas. En el tema de la migración por ejemplo, de gran importancia tanto a nivel mundial como particularmente en Brasil, tenemos numerosas estadísticas acerca de la procedencia de los migrantes, la proporción de hombres y mujeres, los salarios comparativos, etc. (hay que tener en cuenta sin embargo, que aún estas estadísticas oficiales pueden tener severas limitaciones: por ejemplo, en Estados Unidos se estima que tal vez haya dos veces más nativos de las Indias Occidentales que los que legalmente entraron y las cifras respecto a los mexicanos son todavía más dudosas), pero la información que arrojan no puede explicar por sí misma porqué las personas de algunas culturas migran frecuentemente y otras no, por esto, los informes narrativos son esenciales. Por ejemplo, en Inglaterra cerca del $90 \%$ de restaurantes hindúes son manejados por familias originarias de una pequeña ciudad de Bangladesh: Sylhet, ubicada en el delta del río Ganges. A partir de sus historias de vida se puede descubrir que estas personas, tradicionalmente navegantes expertos de las vastas redes de canales fluviales y crecidas estacionales, se convirtieron en tripulantes de la marina mercante británica entre las décadas de 1920 y 1940. Algunos se establecieron en los puertos británicos y unos pocos instalaron restaurantes para abastecer a su propia e incipiente comunidad. Su éxito puso en marcha una dramática cadena migratoria en la última parte del siglo. Desde las estadísticas puede estimarse el número de familias bangladíes inmigrantes, si sus hombres y mujeres tienen trabajos pagos, aún sus ingresos y pobreza relativa. Pero sin una descripción a fondo, es imposible entender porqué han venido a Inglaterra determinadas familias y vecinos y no otros, cómo han experimentado el moverse entre dos culturas tan marcadamente diferentes, qué significa para una mujer bangladí transitar portando un velo por las altamente sexualizadas calles de un país occidental, cuáles son sus deseos y aspiraciones para el futuro. La historia oral nos puede decir esto no sólo acerca de ellos sino de una interminable serie de grupos migratorios, en Brasil o en otras partes del mundo.

Un segundo ejemplo de la potencialidad que tiene la combinación de ambos tipos de evidencia, es la dinámica del cambio demográfico. La mayoría de los países en el mundo están preocupados ya sea por el estancamiento o caída de sus población (como ocurre mayormente en Europa) $\mathrm{o}$, más comunmente, por el excesivamente rápido nivel de crecimiento de 
la misma que amenaza con condenarlos a una pobreza perpetua. Los intentos gubernamentales para incidir sobre las tendencias de la población raramente han tenido un claro impacto. Por ejemplo, tanto la Italia fascista como la Rusia comunista llevaron a cabo sostenidos pero totalmente ineficaces intentos para elevar la tasa de nacimiento en sus países. Una vez más, desde hace mucho tiempo una serie innumerable de estadísticas sobre el tema han estado disponibles pero la problemática a la que apuntaban estaba basada en las presunciones del sentido común de la clase media. En la década de 1970, Diana Gittins llevó adelante una investigación de historia oral como parte de un M.A.2 en la Universidad de Essex, sobre la transmisión de conocimiento de técnicas de control de la natalidad entre mujeres de la clase obrera. Hasta entonces, se había dado por sentado que el conocimiento sobre el control de la natalidad fue adquirido primero por las clases medias educadas y difundido luego al resto de la población a través de ellas. Pero en sus primeras veinte entrevistas, Gittins descubrió que aquellas mujeres de clase obrera más cercanas a las clases medias, como las empleadas domésticas, no obtenían ningún conocimiento de éstas, mientras que las mejor informadas eran las mujeres que trabajaban juntas en fábricas y oficinas y que intercambiaban información entre ellas mismas, independientemente de la burguesía.

Hubo así más de una corriente de influencia social de clase en la reducción del tamaño de la familia en Gran Bretaña entre finales del siglo XIX y mediados del siglo XX. En suma, la importancia de la cultura burguesa en esta transformación había sido groseramente sobreestimada. También se había supuesto que el agente crucial en la introducción de la contracepción había sido el varón y esto se reflejó en las estadísticas mismas, que marcaban los niveles de fertilidad solamente por la ocupación de los maridos. Con las hipótesis deducidas de sus primeras entrevistas de historia oral, Gittins fue capaz de reanalizar las estadísticas para su libro Fair Sex, y demostrar que la ocupación de las mujeres fue tan crucial como la de los hombres en la determinación del tamaño de las familias de clase obrera.

A la inversa, como historiadores orales debemos poner especial cuidado en no extraer conclusiones forzadas de nuestros entrevistados. En cada proyecto necesitamos prestar especial atención a la formulación de estrategias apropiadas para la selección de las muestras. Por supuesto que hay diferentes tipos de muestras posibles y para crear una totalmente representativa tal vez debemos tomar una sub-muestra de un estudio o grupo de estudios ya existentes o bien llevar adelante un nuevo muestreo, ya sea 
Historia, memoria y pasado reciente

a nivel local o nacional. Otra alternativa, especialmente aplicable para interpretar cambios sociales, es tomar una muestra de familias y entrevistar dos o más generaciones pertenecientes a las mismas o bien utilizar abordajes más flexibles como una "muestra estratégica" o deliberada, cuando el plan de muestra evoluciona en respuesta al hallazgo de los primeros entrevistados. Siempre hay que tener en cuenta que diferentes proyectos con objetivos y problemas distintos requieren soluciones diferentes.

El punto clave es que los historiadores orales siempre deben considerar las implicancias cuantitativas de su investigación, adoptando una estrategia de muestreo que se ajuste a sus objetivos y con capacidad explicativa tanto a nivel cualitativo como cuantitativo.

¿Cuáles son, en términos temáticos, las fuerzas y potencialidades para las investigaciones de la historia oral? Quisiera enfatizar cuatro: voces ocultas, esferas escondidas, tradición oral y establecimiento de conexiones entre vidas.

En primer lugar, las voces ocultas. De hecho, cada hombre y mujer tiene una historia de vida histórica y socialmente interesante que contar. En general, tenemos acceso a muchas historias de vida de personas pertenecientes sectores poderosos y privilegiados: hacendados, abogados, sacerdotes, hombres de negocios, banqueros, etc. Pero la historia oral tiene el singular poder de permitirnos acceder también a las experiencias de aquellas personas cuyas vidas están al margen del poder y cuyas voces permanecen ocultas porque sus vivencias improbablemente sean documentadas en los registros. Estas voces escondidas pertenecen sobre todo a las mujeres y por ello la historia oral ha sido tan fundamental en la creación de la historia de género, pero incluyen también a muchos otros sectores sociales como los trabajadores no sindicalizados, la población pauperizada, los discapacitados, los sin techo o los grupos marginados. En Brasil pueden incluirse en esta categoría los pueblos indígenas, las comunidades rurales de ex esclavos que viven en quilombos y sobre todo, las familias de las favelas de las grandes ciudades.

En segundo lugar, las esferas escondidas, esto es, los aspectos de la mayoría de las vidas de las personas que raramente aparecen representados en los registros históricos. Probablemente, la esfera más importante de todas sea la de las relaciones familiares, incluyendo las diferentes experiencias de la infancia que cruzan todas las escalas sociales, desde los sectores más privilegiados hasta los chicos de la calle en las grandes ciudades. Sin embargo, hay un área descuidada tanto por los historiadores orales como por otros, y es la experiencia de la ancianidad. La vejez 
es una experiencia extraordinariamente oculta, a menudo concebida como una fase de manso retiro y decadencia, pero como pude descubrir en las entrevistas realizadas para mi libro I Don't Feel Old (1990) representa, por el contrario, una etapa altamente desafiante de cambios radicales, en la cual las personas tienen que utilizar creativamente las experiencias más tempranas de su vida para luchar contra la depresión y la enfermedad. Fue sorprendente cómo algunos de los más vitales entrevistados se habían lanzado hacia nuevas actividades, como el caso de una mujer que se dedicó a los arreglos florales encontrando en esta actividad una conexión con su padre que había sido artista, u otros que se habían vuelto a casar, encarando un nuevo período de juvenil romanticismo a pesar de la edad.

Otra esfera escondida es la del crimen, la violencia y las drogas. El abordaje de un trabajo contemporáneo sobre esta problemática es difícil $\mathrm{y}$ a veces peligroso, pero ha sido uno de los temas principales de la escuela de historias de vida de Chicago. También es posible entrevistar viejos ex criminales y en este sentido, han habido algunos valiosos libros basados en testimonios de hombres que permanecen aún en prisión.

Una tercera esfera oculta es la cultura informal del trabajo: desde la fábrica de autos hasta la plantación y molienda de azúcar. En mi propia investigación realizada sobre una fábrica inglesa de automóviles en la década de los ' 80 quedé asombrado por el grado en que los trabajadores eran capaces de mantener una cultura secreta en el trabajo que ni los supervisores podían entender y que se expresaba en actividades recreativas tan disímiles como jugar al ajedrez, leer libros, desollar conejos que cazaban en los terraplenes del ferrocarril, y organizar fiestas de cumpleaños y celebraciones navideñas. En una navidad, por ejemplo, habían creado grandes sistemas de luces intermitentes sobre la línea de montaje, utilizando partes de implementos automotrices, un juego que concluí, representaba también un intento por demostrar que, a pesar de estar condenados a la rutina del trabajo en la línea de montaje, conservaban todavía intactas sus habilidades como verdaderos trabajadores calificados.

Más recientemente, en mis registros sobre la élite financiera de la city londinense para mi trabajo City Lives (1996), encontré que otros juegos igualmente asombrosos habían sido comunes por lo menos hasta los '70 entre corredores de bolsa en la city londinense.

En la Bolsa de Valores, por ejemplo, se generaban frecuentemente incidentes entre ellos surgidos de la práctica de arrojarse unos a otros proyectiles de papel o prenderle fuego a los papeles de trabajos de los demás, 
Historia, memoria y pasado reciente

así como también eran frecuentes las bromas verbales, el griterío y los abucheos. Los corredores de bolsa habían sido en su mayoría educados en internados para varones y como adultos continuaban llevando adelante el mismo tipo de juegos que practicaban en sus colegios. Fue solamente cuando se vieron obligados a admitir mujeres que la atmósfera de "club" se desvaneció y modales más serios se convirtieron en norma. No sorprende por tanto que esta cultura de trabajo sea escasamente referida en las historias oficiales sobre el mundo financiero.

Otro aspecto del mundo financiero ha sido expuesto recientemente por Junko Sakai, quien ha completado su investigación en Essex sobre los bancos japoneses en Londres. Su estudio es fascinante: encontró que el personal masculino japonés e inglés mantenía culturas de trabajo completamente separadas. Excepcionalmente, algunos japoneses fueron influenciados por la insistencia de sus colegas ingleses en concluir el horario laboral a las $5.30 \mathrm{pm}$ y comenzaban a abandonar la oficina por sí mismos, pero sólo para regresar furtivamente una hora más tarde. Sin embargo, en general ingleses y japoneses encontraban la comunicación directa sumamente dificultosa, con el resultado de que el funcionamiento de los bancos dependía completamente del rol articulador jugado por el personal japonés femenino que había sido contratado localmente en Londres y que mayormente había elegido migrar a Inglaterra y casarse con hombres ingleses para escapar a las restricciones sociales a las que las mujeres debían enfrentarse en Japón. Esta fisura en la cultura laboral ofrece una explicación al llamativo fracaso que estos bancos japoneses han experimentado en el contexto occidental.

En tercer lugar, se encuentra el campo de los mitos y las tradiciones orales. Los mitos y las tradiciones pueden ser considerados desde diferentes ángulos: como instancias de formación social de la memoria, como folklore, como deformaciones de la verdad histórica, como invenciones de la tradición, etc. Para mí, los ángulos más salientes son los que refieren directamente a la experiencia de vida contemporánea. Tanto en Norte como en Sudamérica, las tradiciones orales se han transformado en una forma clave de evidencia en las luchas por los derechos de la tierra de la comunidades indígenas y también de los negros libres de los quilombos. El meticuloso estudio oral realizado por Hugh Brody en Maps and Dreams sobre el territorio de caza de un grupo de indios canadienses, es un ejemplo modélico de este tipo de trabajos. Y como Raphael Samuel y yo sostuvimos en The Myths We Live By (1990), los mitos y las tradiciones pueden ser también cruciales para la identidad cotidiana y la lucha en 
muchas esferas y puede corroborarse en situaciones muy distintas: en la apelación que hacen en sus desfiles a las batallas del s. XVII entre protestantes y católicos en Irlanda, entre judíos y palestinos en Oriente Medio, entre hombres y mujeres en el trabajo o entre generaciones dentro de una misma familia.

Las influencias transgeneracionales en las familias son un ejemplo fascinante de cómo las tradiciones pueden ser una mezcla de, por un lado, modelos directamente observables -como el de una abuela que provee a su nieta de un ejemplo de maternidad independiente- y, por el otro, de mitos simbólicos que no obstante pueden ser una poderosa influencia para la formación de identidad. Por ejemplo, en mis actuales registros sobre familias jamaiquinas transnacionales, hasta ahora ni una sola persona ha retrotraído su linaje a un esclavo negro. Los únicos ancestros negros mencionados se refieren a los cimarrones que lucharon por conseguir su libertad. Sin embargo, la mayoría de los entrevistados refiere a algún un antecesor blanco, incluyendo en el caso de una familia a un Highlander escocés vencido, quien había sido transportado a Jamaica en cautiverio como preso político. Hay miembros de muchas de estas familias que aún cultivan las "tierras familiares" transmitidas directamente desde los primeros ex esclavos de su propio linaje a mediados del siglo XIX, por lo que sus apellidos deben haber fácilmente pasado de una generación a otra y todos ellos deben haber tenido más antepasados esclavos que libres, sin embargo y en tanto que familias migrantes transnacionales, esto es, personas viviendo con una gran independencia y determinación, lo que necesitan conocer, y lo que recuerdan, no es la herencia esclavista sino su descendencia de hombres libres.

Una de los ejemplos más destacables de la influencia de las tradiciones familiares sobre el comportamiento de las generaciones posteriores, me fue referido por John Byng-Hall en una entrevista que incluimos en The Myths Whe Live By. John Byng-Hall es descendiente del almirante británico Byng, famoso por haber perdido, aparentemente por su cobardía en combate, la isla de Mallorca a mediados del s. XVIII. Como castigo, fue ejecutado en el alcázar de su propio barco. Byng-Hall afirma que desde esa humillación pública, en cada generación hay ostentaciones de un desmesurado coraje, como el caso de su propio abuelo que, siendo Gobernador de Nigeria, sofocó una rebelión parándose desarmado y solo, vistiendo una túnica blanca, en la cima de una colina (estrategia que funcionó porque los rebeldes lo confundieron con un fantasma), o el caso de su propio padre, que aún en los momentos más álgidos del terror Mau 
Historia, memoria y pasado reciente

Mau, permaneció en su remota granja, durmiendo siempre abrazado a su escopeta. John mismo comprendió cuán internalizado estaba el mito también en él cuando en su juventud, regresando a Inglaterra desde África en barco, fue atacado por la polio y en el delirio provocado por la fiebre soñó que había sido herido por una bala de cañón, al igual que su ancestro doscientos años antes.

Finalmente, en lo que se refiere al potencial temático quisiera enfatizar el poder especial que en el marco de la historia oral tienen las entrevistas que apuntan al registro de historias de vidas al permitir el establecimiento de conexiones. La mayoría de la documentación tiende a ser clasificada en diferentes categorías que no son fáciles de conectar entre sí. Por ejemplo, en lo que respecta a la migración, mientras tal vez haya abundancia de información tanto acerca del contexto original como del nuevo, sólo una historia de vida puede conectar ambos puntos en una narración explicativa que dé cuenta de los dos extremos del proceso: ¿qué tipo de personas elige emigrar y por qué, cuáles son sus logros y qué significan para ellos, por qué deciden quedarse o retornar?

He estado particularmente interesado en las conexiones entre familia y trabajo y éste fue un tema principal en mi análisis sobre las comunidades pescadoras en Escocia publicado bajo el nombre Living The Fishing. En este trabajo me centré en cuatro áreas diferentes, cada una de las cuales presentaba variaciones llamativas en lo que respecta a la estructura familiar y la relación empresarial, llegando a la conclusión de que ambas esferas estaban estrechamente relacionadas. La pesca más exitosa se encontraba en áreas tales como las Islas Shetland o el Estuario Moray, que contaban con botes familiares y donde los niños habían crecido en familias igualitarias y habían sido alentados a pensar por sí mismos desde temprana edad. Esto parecía generar pescadores afanosos e inventivos, capaces de modificar o desarrollar su equipamiento así como de buscar nuevos mercados y áreas de pesca. En contraste, en otros sitios como las Islas Occidentales, donde las familias eran más patriarcales y sometían a los niños a una férrea disciplina en la que se priorizaba la emulación de los mayores y donde los adultos demostraban ser renuentes a las innovaciones, encontré estancamiento o decadencia, un alto porcentaje de alcoholismo entre los varones y violencia familiar. Recuerdo particularmente el relato de un hombre de las Islas Occidentales sobre la historia de su abuelo, quien había regresado de una estadía en Canadá con nuevas ideas, imbuido de las cuales había adquirido un bote de pesca más grande y la mayor carreta del pueblo, experimentando un gran progreso económico 
en poco tiempo. Pero alrededor de dos años después este próspero pescador murió al volcarse la nueva carreta sobre él y entonces el comentario de los isleños ante el suceso fue que el accidente había sido un castigo divino, el pescador había muerto aplastado por el peso de sus propios bienes.

Las raíces sociales de la creatividad individual continúan siendo uno de los principales intereses en mi trabajo de historia oral. Más recientemente he estado registrando historias de vida de pioneros en la investigación social y aquí, otra vez, un análisis completo de las mismas hace posible establecer sorprendentes conexiones: por ejemplo, en mi entrevista a Peter Townsend, quien durante los últimos cincuenta años ha sido el principal investigador británico sobre pobreza, ancianidad y familia, surgió el hecho de que él mismo es el hijo único de una madre soltera, por lo que el tema de la crisis de la familia ha representado una problemática que lo involucra personalmente. En el mismo sentido, en la Colección Nacional de Historia de Vida de la Biblioteca Británica en Londres, hemos estado recopilado entrevistas "en profundidad" con pintores y escultores y, más recientemente, artistas y artesanos, tratando de explorar cómo sus propias vidas habían incidido en su creatividad personal.

La primera vez que vine a Brasil, hace diez años, conocí a un ceramista extraordinario en Pernambuco, Manuel Galdino, quien combinaba técnicas tradicionales con la inventiva temática de un escultor, a la vez que era un notable y fluido improvisador. Ana Dourado, historiadora oral de Recife y yo, proyectamos la realización de un libro sobre Manuel, combinando fotografías de su trabajo, textos de su poesía oral y su propia vida: él estaba entusiasmado y Ana comenzó a entrevistarlo, pero repentinamente y debido a las condiciones de pobreza en que vivía, murió de una enfermedad menor y evitable. Creo sin embargo, que existen en Brasil muchos artistas poco conocidos cuyos testimonios serían muy valiosos tanto para sí mismos como para permitir el acceso a un conocimiento profundo de las pobres pero creativas comunidades de las cuales emergieron.

Permítaseme volver ahora sobre algunos de los desafíos claves con los que deberá enfrentarse la historia oral en el futuro.

En primer lugar nos topamos con un constante problema, el tema de la "verdad", o sea, la naturaleza de la memoria ¿podemos fiarnos de ella? Dado que esta cuestión siempre será fundamental para los historiadores orales, dediqué una sección completa a ella en The Voice of the Past (capítulos 4 y 5), por consiguiente no voy a explayarme aquí sobre el tema. Dicho simplemente, los testimonios combinan dos tipos de contenido. Por 
Historia, memoria y pasado reciente

un lado, pueden redituar mucho en cuanto a valiosa información fáctica, por ejemplo: dónde vivió una persona, su estructura familiar, los tipos de trabajo que desarrolló, etc. -información cuya veracidad puede probarse de varias maneras, pero junto con esto, los testimonios también llevan la igualmente reveladora marca de la fuerza modeladora de la memoria así como de la conciencia individual y colectiva. Hay silencios, como los que Luisa Passerini notó en las memorias de aquellos que vivieron bajo el fascismo, que pueden representar una marca de cuánto sufrieron estas personas, así como los niños pueden reprimir recuerdos de abuso sexual cometido por un familiar. Y existe también la reconstrucción activa de la memoria en orden a dotar de sentido el pasado vivido o incluso de conectarlo con sueños perdidos, como tan elocuentemente demostró Alessandro Portelli en sus entrevistas a viejos comunistas de Terni, en Italia central.

Portelli mostró cómo muchos, aunque -y esto debe ser destacadociertamente no todos los activistas locales que entrevistó, habían asimilado los recuerdos de una antigua huelga contra el ingreso de Italia a la OTAN en la cual la policía había asesinado a uno de los manifestantes, con la memoria de huelgas posteriores contra las acerías, presumiblemente porque el tema de la OTAN resultó ser pasajero, mientras que la lucha por mantener el empleo fue sostenida durante décadas. Portelli también detalla cómo un viejo comunista, para reconciliarse con una revolución que nunca sucedió, le contó la historia de un pasado que habría podido ser: según su relato, cuando los comunistas tomaron la decisión crucial de participar en las primeras elecciones de posguerra en lugar de seguir la lucha armada como partisanos, él mismo había hablado con su líder nacional Togliatti, a quien advirtió sobre la pérdida de esa oportunidad única diciéndole: "Como dice Marx, cuando el tordo está volando es el momento para disparar". De hecho, ni el entrevistado había tenido jamás la ocasión de mantener esta charla personal con el líder del PC, ni Marx había dicho nada parecido acerca de los tordos; en verdad, la cita era un proverbio tradicional de los campesinos de la Italia central. Pero, aunque en ambos ejemplos las memorias recolectadas por Portelli eran objetivamente falsas, proporcionan en cada caso -precisamente por la forma en que los entrevistados cambiaron o inventaron recuerdos sobre algunas experiencias- una vívida evidencia de cómo la conciencia de los militantes comunistas locales se desarrolló como respuesta a los acontecimientos así como el modo en que fueron capaces de entrecruzar su marxismo con la antigua cultura popular de su región. 
Esta reconstrucción de la memoria también puede revelarse respecto de los valores familiares y es especialmente posible que emerja entrevistando a más de una generación perteneciente a una misma familia. Por ejemplo, recientemente entrevisté en Gran Bretaña a una mujer jamaiquina mayor que había trabajado como enfermera y había sido una activa figura en una de las iglesias quien refirió un sincero relato sobre su matrimonio con un pastor y sobre sus hijos. Pero no fue sino más tarde, cuando entrevisté a su nieta, que comprendí algunos aspectos que no aparecían explicitados en la entrevista: que la mujer había tenido a su hijo mayor como madre soltera antes de conocer al pastor, si bien ambos habían criado a este niño como propio y que además, después de la muerte del pastor ella había tenido un segundo, breve y fracasado matrimonio. En un contex to jamaiquino ampliado, una historia familiar como ésta sería completamente normal, de hecho la mayoría de las mujeres tuvieron sus hijos fuera del matrimonio; pero para mi entrevistada, esta especie de corrección de su historia era claramente beneficiosa para su identidad y respetabilidad como referente de su iglesia.

Una vez más, y para sintetizar, diré que tenemos tanto que aprender acerca de la reconstrucción de la memoria como de los hechos mismos, $\mathrm{y}$, en este caso, ambos surgen de los registros orales. El problema de la memoria siempre será una cuestión fundamental para los historiadores orales, pero creo que debemos abordarlo teniendo en cuenta la doble fuerza, objetiva y subjetiva, que contiene la historia oral.

Un segundo y más reciente desafío fue introducido por el nuevo entusiasmo por leer las entrevistas como narraciones. Hay muchos recursos para su abordaje, desde las técnicas especiales para la interpretación desarrolladas por Gabriele Rosenthal para entrevistar a viejos nazis alemanes pasando por el análisis literario de géneros autobiográficos y discursivos, hasta las perspectivas antropológicas sobre la conformación de los registros producidas por el contexto y el género que tan persuasivamente ha fundamentado Elizabeth Tonkin en su libro Narrating Our Pasts. He encontrado fascinantes las perspectivas ofrecidas por el abordaje narrativo y en coautoría con Mary Chamerlain edité recientemente un volumen de artículos sobre el tema: Narrative and Gener (1998).

No hay ninguna duda que se puede aprender mucho de la lectura de nuestras entrevistas a partir de esta clase de sensibilidad. Es muy sorprendente, por ejemplo, cuán diferentes pueden ser el lenguaje y el estilo de una historia de vida cuando el narrador es alguien habituado a las presentaciones públicas: la frase bíblica en el activista de la iglesia, por 
Historia, memoria y pasado reciente

ejemplo o las destrezas en contar anécdotas adquiridas por un hombre que ha pasado muchas noches contando historias en el bar local. Generalmente, también hay notables contrastes entre la forma en que hombres y mujeres narran sus historias de vida: los hombres enfatizan un "yo" activo, poniéndose a sí mismos en el centro de la escena, mientras que las mujeres mucho más frecuentemente enfatizan el concepto de "grupo", utilizando el pronombre "nosotros" o el término neutral "uno". Una notable y entretenida descripción de cómo hombres y mujeres difieren en las conversaciones cotidianas puede ser leída en el libro You Just Don't Understand de Deborah Tanner.

Hay que advertir sin embargo, que aunque todo esto sea completamente válido, se corre un serio peligro: muchos historiadores orales están tan absorbidos en la lectura de los testimonios desde una perspectiva que prioriza los aspectos narrativos y que se centra casi exclusivamente en cómo los entrevistados dicen lo que dicen, que dejan de lado la ineludible reflexión sobre qué es lo que los éstos realmente están expresando. Por eso creo que si bien es necesario ser sensible al aspecto narrativo, no se debe ir demasiado lejos en esa dirección porque se corre el peligro de perder todos aquellos propósitos originales y potencialidades de la historia oral.

Un tercer y también nuevo desafío se encuentra en las oportunidades de compartir nuestro material. Una parte considerable del trabajo en historia oral, especialmente en Estados Unidos, está archivado y consiste en proyectos originalmente destinados a crear fuentes biográficas públicas. Pero muchas otras entrevistas son realizadas en el marco de investigaciones específicas y en estos últimos casos, generalmente una vez que los trabajos son publicados, las cintas y grabaciones languidecen en algún estante en las casas u oficinas de los investigadores, no disponibles para otros y son en general desechadas cuando el investigador se muda o se retira. Muchas veces, este tipo de entrevistas "en profundidad" son realizadas por sociólogos tanto como por historiadores orales, sin embargo, en ambos casos contienen el mismo valor potencial como recursos para otras investigaciones.

Al principio me interesé en esta situación porque habíamos decidido dejar las transcripciones de las entrevistas realizadas para The Edwardians como un archivo informal en Essex y de hecho un gran número de personas las han utilizado; alrededor de diez publicaciones de otros investigadores se han basado en este material que he puesto a disposición, lo que para mí es una inesperada fuente de gratificación y placer. 
Hacia fines de la década de 1980 estuve en condiciones de establecer la Colección Nacional de Historia de Vida en el Archivo de Sonido de la Biblioteca Nacional Británica creada en primera instancia como un centro nacional para el archivo de historia oral y que luego se convirtió en un espacio destinado tanto a conservar como a generar material. En ese marco, pudimos llevar a cabo una acotada recopilación de investigaciones sociales que mostraron tanto las entrevistas como las notas de campo de los proyectos significativos desarrollados desde la década de 1950, de los cuales solamente un 10\% había sido archivado y el resto estaba prácticamente destruido o corría serio riesgo de perderse. En 1994, el Consejo de Investigación Económica y Social fundó el "Qualidata" a través del cual hemos localizado y rescatado el más preciado material temprano y estableció una política para proteger el material de entrevistas que surjan de futuras investigaciones.

Sin embargo, uno de los riesgos que se corren es poner demasiado esfuerzo en generar o conservar entrevistas que nadie usará en el futuro, por ello existe una necesidad urgente de compartir la experiencia internacional sobre este punto. Estoy particularmente impresionado por la política que viene llevando adelante Suecia en esta materia, a través del apoyo a la generación de material autobiográfico sobre una base regular como un recurso disponible en las bibliotecas públicas, las escuelas y el sistema universitario. Por nuestra experiencia en Gran Bretaña, podemos decir sin embargo que el grupo entrevistas más probablemente consultada es, en primer término, aquél basado en algún tipo de muestreo nacional o regional, en segundo lugar, las historias de vidas completas, sustancialmente profundas, que abarcan una amplia gama de temas y en tercer término, material transcripto, compendiado y organizado temáticamente. Con el nuevo material, todos los textos pueden ser computarizados y las grabaciones digitalizadas de modo tal que una vez escogido y organizado, habría nuevas posibilidades de ponerlo a disposición de bibliotecas y del sistema educativo y de investigación.

Y es entonces aquí donde nos encontramos con nuestro cuarto desafío, el de las nuevas tecnologías de la comunicación. ¿Debemos considerarlas como una extraordinaria oportunidad o reconocerlos como los portavoces de nuestro olvido futuro? Después de todo, la historia oral como la conocemos fue indudablemente hija de la dorada época del sonido, cuando la radio era la vanguardia de la comunicación de masas, una era que ya ha pasado largamente al olvido. Personalmente no creo que los logros de los historiadores orales devengan de las condiciones de los adelantos 
Historia, memoria y pasado reciente

técnicos, de hecho, muchos de los videos de historia oral que se han producido son muy rígidos y repetitivos porque sus realizadores no han captado la necesidad de aplicación de técnicas diferentes para lograr que el producto audiovisual transmita su mensaje atrayendo al mismo tiempo el interés de los espectadores. Lamentablemente, las mismas debilidades se repiten en la mayoría de los proyectos sobre historia oral realizados con técnicas de multimedia en CD's que he tenido oportunidad de observar.

Por otro lado, sin embargo, no podemos desconocer que tanto la potencial audiencia como el alcance que la historia oral puede adquirir a través de los medios modernos de comunicación, es enorme. Por ejemplo, un programa reciente basado en testimonios filmados en Gran Bretaña producido por Steve Humphries, narraba las historias de mujeres que habían vivido en los hogares "Magdalena" en Irlanda, lugares sospechados de irregularidades sexuales. De hecho, con frecuencia estas mujeres eran víctimas de abusos por parte de figuras locales prominentes como algunos clérigos y por lo tanto eran encerradas en estos hogares como una forma de silenciarlas. Pero aún peor era el tratamiento al que se las sometía, días enteros de duro trabajo a lo que se sumaba la brutalidad física de las monjas y los asaltos sexuales por parte de sacerdotes visitantes. Cuando se filmó el programa, ninguna de las protagonistas que aún vivía en Irlanda autorizó a que sus memorias fueran transmitidas, por lo cual el documental tuvo que basarse en los testimonios de mujeres que habían inmigrado posteriormente a Inglaterra. Pero cuando el canal de televisión proporcionó una línea telefónica de ayuda durante los tres días siguientes a la emisión del programa, se recibieron alrededor de 400 llamados de mujeres desde la República de Irlanda reportando experiencias similares. Este es un caso en el cual la transmisión de voces ocultas ayudó a despertar la conciencia nacional sobre estos hechos.

Hay también nuevas y excitantes posibilidades para la difusión de la historia oral a través de canales de multimedia y de internet. El formato de multimedia tiene un potencial especial debido a que integra sonido, imágenes y texto y puede tal vez transformarse en una vía importante para atraer a un público más joven. La creación de sitios en internet y la combinación de diferentes tipos de documentos abren también perspectivas nuevas y prometedoras. Varios proyectos de historia oral en Europa y América han sido producidos en estos nuevos formatos, pero con mucha frecuencia no resultan dinámicos a la vez que carecen de un diseño ágil. En este sentido, el trabajo realizado en el Museo da Pessoa en San Pablo, 
que abarca una amplia gama de temas -sindicatos, grandes empresas, clubes de fútbol, viajantes de subterráneos, etc.- es pionero en elegancia y sofisticación.

Nuestro último desafío es esclarecer el papel que le cabe a la historia oral en la formación de la identidad en una era globalizada. En este sentido, creo que la influencia de la globalización y las tendencias hacia un mundo cultural homogéneo producidas por nuestra creciente integración en el marco de una economía global, hacen mucho más necesario el fortalecimiento de nuestras raíces locales. El sentido de pertenencia, de identidad común y de comunidad puede ser crucial para permitir el desarrollo de la acción social a nivel local y la historia oral puede contribuir indudablemente a ello. Para el trabajo titulado Listening for a Change, he desarrollado un estudio de caso de dos favelas en Recife: Brasilia Teimosa y Casa Amarela, en las cuales la creación de una historia colectiva que es enseñada ahora en las escuelas locales sobre la forma en que se realizaron las ocupaciones de tierra, se transformó en un estímulo muy importante para el desarrollo de la exitosa campaña por la posesión de la tierra y la provisión de servicios de agua potable y electricidad, que finalmente fueron concedidos por el Municipio de la ciudad.

Creo también que la historia oral tiene un gran potencial en la generación de entendimientos humanos internacionales, el más extendido en este sentido es el utilizado por las $\mathrm{ONG}^{\prime}$ s en su búsqueda de contribuciones para fondos destinados a paliar las consecuencias de desastres. Podemos también utilizar la historia oral para entender más acerca de las personas que viven transnacionalmente, entre quienes se destacan también aquellos que forman parte del personal de las ONG's, tal como se refleja en el estudio realizado por Andra Zhouris sobre veteranos británicos que trabajan en la preservación de la selva amazónica. En poco tiempo, con la computarización de las traducciones quizás sea posible crear un banco internacional y plurilingüístico de historias de vidas en internet, que signifique no sólo una fuente de recursos sino simplemente una vía a través de la cual gente común de diferentes nacionalidades pueda conocer más acerca de otros y descubrir cuánto tienen en común entre ellos. Desde una perspectiva más dramática y después de presenciar los a veces terroríficos testimonios del apartheid en las audiencias de la Comisión Sudafricana por la Verdad televisados diariamente a toda la nación ¿cabe imaginar el papel que puede jugar la historia oral en tender un puente en conflictos tan profundamente arraigados como los de Irlanda del Norte o el Medio Oriente? 
Historia, memoria y pasado reciente

Para concluir, quisiera expresar mi convencimiento acerca del rico potencial abierto a la historia oral en el presente y hacia el futuro, tanto en Brasil como internacionalmente. Aprender a escuchar es una habilidad humana fundamental: ella está allí para ayudarnos a entender nuestro pasado en forma más acabada a través de la creación de memorias nacionales pero también para construir un mejor y más democrático futuro. 